\title{
Modafinil Dependence and Hypersexuality: A Case Report and Review of the Evidence
}

\author{
Sahoo Swapnajeet, Subodh BN, Gupta Gourav \\ Department of Psychiatry, Postgraduate Institute of Medical Education \& Research, Chandigarh, India
}

\begin{abstract}
Apart from sleep wake disorders, nowadays, modafinil is being prescribed for several psychiatric disorders including depression. Despite being reported as to be having very low abuse potential, cases of modafinil dependence had come to the limelight. In this case report, we describe a 35 year old man with bipolar affective disorder while in remission who developed modafinil dependence and later on, had hypersexuality when he increased the dose of modafinil from 400 to 1,000 mg/day. Existing literature suggests that modafinil when taken above prescribed doses can cause many side effects ranging from nausea, vomiting to psychotic exacerbation and mania. However, hypersexuality as a side effect of modafinil overuse is not commonly seen. The exact pathophysiological mechanism of modafinil induced hypersexuality is not clear. Clinicians should be aware of possibility of modafinil leading to dependence and this rare significant side effect of modafinil.
\end{abstract}

KEY WORDS: Modafinil; Drug dependence; Increased libido.

\section{INTRODUCTION}

Modafinil, a novel wake-promoting drug has gained immense popularity among psychiatrists in recent times. Now a days, its use is not limited to treat narcolepsy and other sleep wake disorders, but also in chronic fatigue syndrome, treatment resistant depression, attention deficit hyperactivity disorder and cocaine dependency. ${ }^{1)}$ Reportedly it has a much lower abuse potential but some have also suggested it to be having a definite potential for dependence. ${ }^{2)}$ Here we report a rare case of modafinil dependence who presented with hypersexuality behavior. Till date, only one such similar case have been reported. ${ }^{3)}$

\section{CASE}

A 35 years male patient was diagnosed with bipolar affective disorder (International Classification of Diseases [ICD]-10 criteria), since last 7 years with four episodes of depression (characterized by low mood, decreased en-

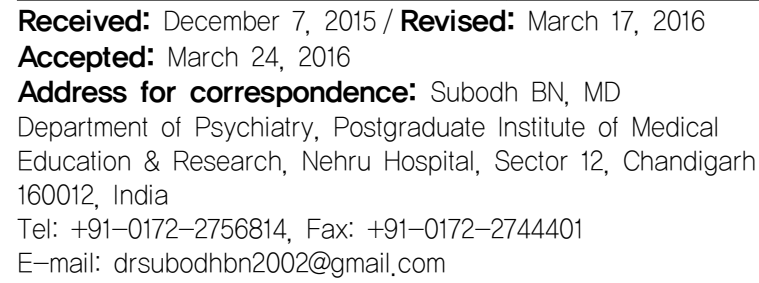

ergy, anxiety throughout the day, depressive cognitions, decreased sleep and appetite along with occasional wish to die) and two episodes of mania (characterized by cheerful mood, increased activity levels, decreased sleep to only 3 hours/day, increased appetite, grandiose ideas, over-talkativeness and increased expenditure) along with benzodiazepine dependence (currently abstinent). He presented to our centre seeking treatment for excessive sexual desire and to limit excessive use of modafinil. He was on lithium (600 mg/day), carbamazepine ( $800 \mathrm{mg} /$ day $)$, venlafaxine (150 mg/day), and lamotrigine (200 mg/day) during this period. Exploration of the history revealed that, he was started on modafinil $200 \mathrm{mg} /$ day (100 mg at morning and afternoon) by a private practitioner four years earlier to improve his fluctuating sadness of mood and early morning lethargy. He would feel active, fresh, and would be able to work better after taking modafinil. Over the next 3 years (2010 to 2012) he started to use modafinil whenever he used to feel low and escalated the dose to 400-600 $\mathrm{mg} /$ day. Whenever he would not take, he had strong craving for the same, felt low, lethargic, tired, aches and pains in body, decreased confidence and concentration at work. In mid of 2014, inspite of good compliance to above medications, without any apparent stressors, he again started to have persistent sadness, lack of energy and easy fatigability. He started to skip work and would keep lying on bed. Because of this, he increased dose of modafinil to 400

(c) This is an Open-Access article distributed under the terms of the Creative Commons Attribution Non-Commercial License (http://creativecommons.org/licenses/by-nc/4.0) which permits unrestricted non-commercial use, distribution, and reproduction in any medium, provided the original work is properly cited. 
$\mathrm{mg}$ /day on his own in early morning. After taking modafinil he would feel slightly better for few hours. So, over the next few weeks, he increased the dose to 800-1,000 $\mathrm{mg}$ /day in divided doses. Though there was no improvement in his mood, there was change in his sexual behavior. On seeing any women nearby, he started to have spontaneous erection and feel excited. His frequency of masturbation increased to 10-12 times/day, but he would not feel satisfied unlike his premorbid self. In addition to these symptoms, he started interacting with commercial sex workers (CSWs) on phone, would get aroused by mere talking with them. He started to have increased urge to visit CSWs. On one occasion, he visited a CSW though did not have physical contact. He felt ashamed and worried about his lack of self-control. He would be preoccupied with sexual fantasies and would not be able to concentrate at his work. He tried meditation, increased his frequency of religious activities to get rid of his sexual urges but in vain. Despite being happily married for last 16 years with adequate sexual adjustment he would have increased desire for intercourse with females other than his wife which would further instigate guilt in his mind. His sleep was disturbed with restlessness and anxiety at night and he would feel fatigue throughout the day despite taking high doses of modafinil. His mood remained sad for most part of the day, would not enjoy the day to day activities like before and continued to harbor depressive cognitions. There was no associated history of cheerfulness, grandiosity, hyperactivity, overplanning, increased appetite and decreased need for sleep during this time. Throughout this period there was neither any change in his compliance with medications nor any change in dosage of other medications. And he had been on venlafaxine $150 \mathrm{mg}$ /day since last 2 years under the cover of three mood stabilizers, i.e., lithium, carbamazepine, and lamotrigine with adequate dosages and normal therapeutic lithium level of $0.76 \mathrm{mmol} / \mathrm{L}$.

None of previous mood episodes (both depression and mania) had any symptoms suggestive of hypersexual behavior. His sexual behavior during the intake of high doses of modafinil was also not in keeping with his premorbid sexual desire and sexual activity. Detailed evaluation of history did not suggest presence of any head injury in the recent past and presence of any associated impulsivity, obsessive compulsive behavior, substance abuse, hyperorality, cognitive decline, sleep attacks, use of aphrodisiacs and use of any other medications which could increase the sexual desire.

With the above available information, a diagnosis of bipolar affective disorder with current episode mild depres- sion (as per ICD-10 criteria) along with an additional diagnosis of modafinil dependence and modafinil induced hypersexuality. He was admitted in our centre. Physical examination, routine hematological and biochemistry investigations and electrocardiogram were within normal limits. At 800-1,000 mg/day of modafinil, he had side effects as assessed by UKU scale in areas of psychic (score 9), autonomic (score 3), other (score 9) and global assessment of interference (score 3). He was also rated on Hypersexual Behavior Inventory-19 (HBI-19) ${ }^{4)}$ where he scored 48. Management included a gradual and slow reduction in dosage of modafinil at the rate of $100 \mathrm{mg}$ every 2 days under the cover of benzodiazepines (clonazepam 2 $\mathrm{mg}$ /day) to manage withdrawal symptoms. Mood charting was done to assess development of any mood symptoms. Over 3 weeks period, all the above mentioned symptoms decreased significantly (UKU total score 0 ; HBI-19 total score 19) and he was discharged after being counseled with structured relapse prevention programme on lithium (600 mg/day), lamotrigine (200 mg/day) and venlafaxine (150 mg/day).

\section{DISCUSSION}

In literature, we could find only two case reports on modafinil dependence at higher doses. ${ }^{2,5)}$ As seen in the index case, modafinil seems to have some abuse potential. The pattern of use was characterized by craving, tolerance and withdrawal. The withdrawal symptoms were mostly nonspecific, opposite to effect it produces. Our case escalated the dose of modafinil so as to overcome fatigue, increase energy and improve concentration. Later on, to overcome the fear of relapsing into depression he increased to a supratherapeutic dosage of $1,000 \mathrm{mg} /$ day and started having symptoms which fulfilled the criteria of hypersexuality disorder (as per Kafka's criteria). ${ }^{6}$ These symptoms were temporally correlated with increment in dose of modafinil and subsided on decreasing the dose of the same in a controlled environment. Hence, as neither any other drug used in the index case could be linked with such kind of behavior nor was there any switch to mania/hypomania/mixed episode which could explain such change in behavior, we concluded that the symptoms of hypersexual behavior was induced by modafinil. Hypersexual behavior during a hypomanic/manic or mixed episode has characteristics of sexual disinhibition, severely compromised self-control, lack of guilt and shame feelings and is generally without any insight. In contrast, index case had guilt associated with his increased sexual de- 
sire which is very well reported in individuals with hypersexual behaviour. ${ }^{7,8)}$

Modafinil has been found to act by binding on dopamine receptors and affects dopamine uptake by dopamine transporters in the neurons. Modafinil dependence can be explained by its dopamine uptake blockade leading to increase in dopamine concentration in the brain areas linked with reward pathways. ${ }^{9)}$ On the other hand, a hyperdopaminergic state have been implicated in hypersexuality. Upsurge of dopamine in the mesolimbic pathway due to use of supratherapeutic dosage of modafinil might explain for the development of hypersexuality in the index case.

Overdose of modafinil can cause insomnia, agitation, tachycardia, rise in blood pressure etc., but in case of dependence it is more likely to cause physical withdrawal symptoms like lethargy, tremors of hands, anxiety and erratic sleep hours ${ }^{5)}$ or only severe psychological withdrawal symptoms. ${ }^{10)}$ Modafinil has been listed under schedule IV drug in United States for regulation of its sale. However, in India, it is available over the counter and being regularly prescribed by many psychiatrists. Inspite of reportedly low abuse potential, we report a case of modafinil dependence and modafinil induced hypersexuality so as to increase awareness regarding this rare side effect of modafinil and for the need of regulation on its sale.

\section{REFERENCES}

1. Joos L, Docx L, Schmaal L, Sabbe BG, Dom G. Modafinil in psychiatric disorders: the promising state reconsidered. Tijdschr Psychiatr 2010;52:763-773.

2. Kate N, Grover S, Ghormode D. Dependence on supratherapeutic doses of modafinil: a case report. Prim Care Companion CNS Disord 2012;14:PCC.11101333.

3. Bulut SD, Tulaci RG, Türkoğlu S, Bulut S, Örsel S. Hypersexuality after modafinil treatment: a case report. $J$ Pharm Pharmacol 2015;3:39-41.

4. Reid RC, Garos S, Carpenter BN. Reliability, validity, and psychometric development of the hypersexual behaviour inventory in an outpatient sample of men. Sex Addict Compuls 2011;18:30-51.

5. Krishnan R, Chary KV. A rare case of modafinil dependence. J Pharmacol Pharmacother 2015;6:49-50.

6. Kafka MP. Hypersexual disorder: a proposed diagnosis for DSM-V. Arch Sex Behav 2010;39:377-400.

7. Reid RC, Temko J, Moghaddam JF, Fong TW. Shame, rumination, and self-compassion in men assessed for hypersexual disorder. J Psychiatr Pract 2014;20:260-268.

8. Gilliland R, South M, Carpenter BN, Hardy SA. The roles of shame and guilt in hypersexual behaviour. Sex Addict Compuls 2011;18:12-29.

9. Volkow ND, Fowler JS, Logan J, Alexoff D, Zhu W, Telang $\mathrm{F}$, et al. Effects of modafinil on dopamine and dopamine transporters in the male human brain: clinical implications. JAMA 2009;301:1148-1154.

10. Dhillon R, Wu X, Bastiampillai T, Tibrewal P. Could modafinil be a drug of dependence? Aust N Z J Psychiatry $2015 ; 49: 485-486$ 